This item was submitted to Loughborough's Research Repository by the author.

Items in Figshare are protected by copyright, with all rights reserved, unless otherwise indicated.

\title{
Does students' confidence in their ability in mathematics matter?
}

PLEASE CITE THE PUBLISHED VERSION

http://teamat.oxfordjournals.org/content/28/2/53.abstract?sid=3f5f117a-d8e9-4270-a772-a7df88d9c33c

\section{PUBLISHER}

Oxford University Press on behalf of The Institute of Mathematics and its Applications $@$ The authors

\section{VERSION}

AM (Accepted Manuscript)

\section{LICENCE}

CC BY-NC-ND 4.0

\section{REPOSITORY RECORD}

Parsons, Sarah, Tony Croft, and Martin C. Harrison. 2019. "Does Students' Confidence in Their Ability in Mathematics Matter?”. figshare. https://hdl.handle.net/2134/9063. 
This item was submitted to Loughborough's Institutional Repository (https://dspace.lboro.ac.uk/) by the author and is made available under the following Creative Commons Licence conditions.

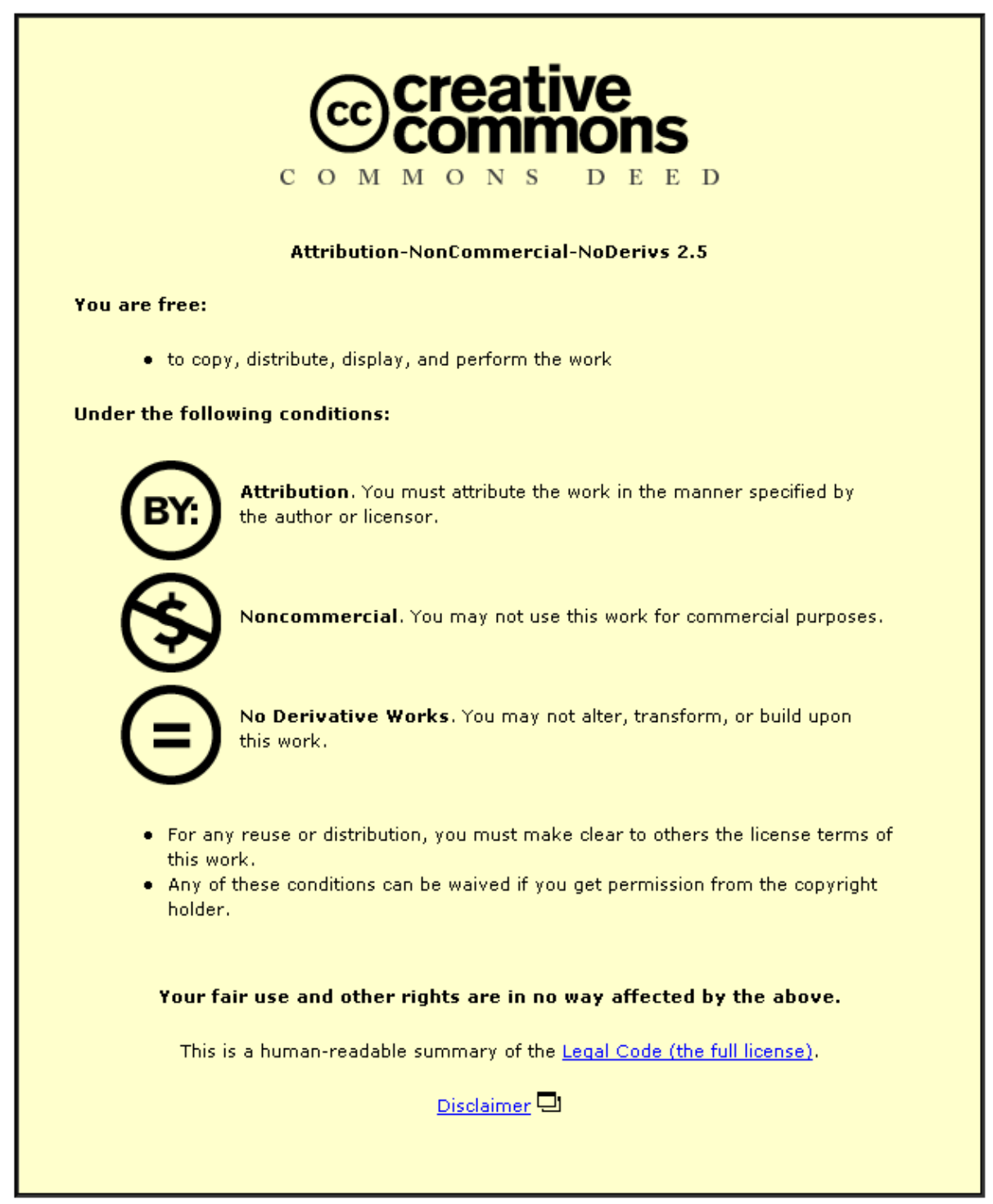

For the full text of this licence, please go to: http://creativecommons.org/licenses/by-nc-nd/2.5/ 


\title{
Does Students' Confidence in their Ability in Mathematics Matter?
}

\author{
Sarah Parsons, Tony Croft, and Martin Harrison
}

\begin{abstract}
Research was conducted into first year engineering students' learning of mathematics in a university college during 2005-7. The aims were to understand better students' confidences and explore which factors affected performance and how these were inter-related.

Questionnaires were administered which posed questions regarding previous mathematics qualifications, student confidences, attitude, liking of the subject and motivation. The responses were analysed and compared with marks achieved by the students in their end of first year engineering mathematics examinations.

The majority of students were fairly confident, reported improved confidence acquired during their first year of university study and had positive attitudes. Better mathematically qualified students were generally more confident and successful in mathematics. A regression model was produced which predicted a 12\% increase in mathematics mark per increase in GCSE mathematics grade, and 5\% increase in mark for each increase in confidence level. Thus, better qualifications (and the skills represented) were shown to be associated with better university marks and student confidence also produced a notable association with the marks achieved.

The findings suggest that having attended to the mathematics syllabi, lecturers could seek to boost student confidence in their ability in mathematics as a further means to improve student performance at university.
\end{abstract}

\section{Introduction}

It is generally recognised that students' past qualifications affect academic achievement at university, hence the need for minimum entry requirements for courses. However sometimes students with lower qualifications work and succeed beyond expectations, while better qualified students struggle. This study sought to investigate students' confidence, liking of the subject, motivation and entry qualifications, and to investigate the effect of these on students' achievement. It was hoped to understand the inter-relations and relative importance of different factors and how the students perceived learning mathematics.

Competence in mathematics is the main desired outcome from university engineering mathematics modules. However, if confidence is found to have an effect on, or relationship with, students' achievement, then should confidence also be considered by university lecturers as a means to improve student achievement? 
This paper describes the background at Harper Adams and nationally, past studies and student difficulties, and the methodology of this research. Results of student questionnaires are presented, including the trends found between GCSE mathematics grades, students' confidence and first year university engineering mathematics marks. Key questions posed in the questionnaires are in Appendix I. Results of ANOVA and Kruskal-Wallis tests and regression analysis are described, and the overall findings are summarised in the conclusions.

\section{Background}

Harper Adams University College is a higher education college in Shropshire specialising in land-based subjects. Engineering honours degrees are offered in Off Road Vehicle Design, Engineering Design and Development, and Agricultural Engineering, for MEng, Beng and BSc. FdSc/HND awards are also available.

BEng and MEng students are required to have three A2 grade C's (B's for MEng). A2 mathematics is recommended but not essential, although some study of mathematics beyond GCSE is; this may be AS level or national diploma mathematics. BSc and HND/FdSc students' mathematics experience is more varied, some have A-level mathematics (as recommended), but the minimum requirement is grade C GCSE mathematics (although some have lower GCSE grades because they have studied mathematics post-GCSE).

Students are taught mathematics in groups by award level, of between 12 and 30 students, in a classroom style room. Students are timetabled two consecutive hours per week, which is divided between teaching/lecturing and working on tutorial exercises. Students are provided with handouts which include theory, worked examples and exercises with answers. Additional help is available in the extra mathematics weekly group times or by individual mathematics support appointments.

Since 2001 mathematics support and a changed module content (including revision of essential mathematics) have much improved student retention and achievement. Currently, mean examination scores are generally in the 60\%'s and 70\%'s, reflecting good progression and achievement.

Recent improvements contrast with past poor retention, especially in 1999/2000 (Parsons, 2005), and with widespread concerns over engineering and science students' learning of mathematics. Hawkes and Savage (2000) refer to the 'serious decline in students' mastery of basic mathematical skills and level of preparation for mathematics-based degree courses. This decline is well-established and affects students at all levels. As a result, acute problems now confront those teaching mathematics and mathematics based modules across the full range of universities.' Much work has been done to document and seek to address the 'mathematics problem', which may be described as the skills gap between what students are expected, or need, to know on arrival at university and what they actually know.

The effect of students' attitudes and confidence is also worthy of consideration. Ernest (1991) wrote of 'growing evidence of the importance of students' attitudes and beliefs about 
mathematics for their achievement and successful applications of the subject.' and proposed cycles of positive attitudes, effort and success for learning mathematics, and contrasting negative cycles (Ernest, 2000). In their report on the mathematical education of engineers, Kent and Noss (2003) described the process to improve students' mathematical confidence as 'a slow process, which cannot be achieved through quick remediation, unlike the problem of "filling in" some gaps in mathematical knowledge'.

One of the aims of a study of single honours mathematics undergraduates in two UK universities was 'to understand better ... why some maintain or develop more positive attitudes than others. ' (Brown et al, 2003). Brown et al found that 'one of the main factors found to influence students' attitudes to mathematics over the course of the study was success at the subject.' Correlations were found between students' knowledge and A-level results, but not with whether students had studied Further Mathematics A-level. Students' attitudes to their studies and social and emotional lives were all found to impact on and influence each other.

The study reported in this paper sought, similarly to the Brown et al study (2003), to understand factors which impacted upon learning of mathematics, but differed in that it investigated first year engineering students in a university college.

Confidence in mathematics is a belief (Fishbein and Azjen, 1975), namely the person's belief that he is able to 'do mathematics'. In the current study three domains of 'confidence' were defined: an Overall Confidence in Mathematics, i.e. a person's belief that he can do mathematics in general, Topic Confidences for particular mathematics topics, i.e. a separate confidence for each topic being considered, and Applications Confidence, i.e. the confidence to apply mathematics skills and knowledge in the future, for example for a project or at work. These three confidence domains are described in greater detail below, and were used in the study to both verify whether confidences could be treated in this way and to explore how confident the students were.

Overall Confidence in Mathematics is a single measure which represents a persons' belief as to whether they can do 'any' or 'all' mathematics. 'I don't have a mathematical mind' and 'I have never felt myself able to learn mathematics' are phrases used by people who have a low Overall Confidence in Mathematics. Low Overall Confidence in Mathematics can result in reduced effort in mathematics, or even mathematics avoidance, because students don't consider that they can succeed and therefore avoid expending what they perceive would be wasted effort. Low Overall Confidence in Mathematics can also be associated with anxiety, and sometimes even panic, regarding doing mathematics. It was considered that high Overall Confidence in Mathematics was beneficial, not simply as a positive outlook, but also because it motivates students to work at mathematics because they believe they can do it. This is then self-fulfilling because their efforts improve their ability and performance. High Overall Confidence in Mathematics is a pre-requisite for independent learning in mathematics. Low Overall Confidence was considered a barrier to learning mathematics, whereas high Overall Confidence was considered an enabler.

Topic Confidence is the student's belief as to whether he can do a particular part of mathematics, for example 'rearrange an equation' or 'differentiate a product'. Each student could have any 
number of topic confidences depending on the list of topics which are being investigated, because he would have a Topic Confidence for each topic. Confidence at any one topic will vary greatly depending on a range of criteria, including: whether the student has even studied this topic, whether they understood it, whether they can remember it, and the perceived level of difficulty, etc. Students' Topic Confidences. i.e. their believed ability in particular mathematics topics, were assessed at Loughborough University (Armstrong and Croft, 1999, and Croft, 2005), Curtin University of Technology in Australia (Frid et al, 1997) and at the University of Southern Queensland (Carmichael and Taylor, 2005). These studies were used to determine students' needs for additional support.

Applications Confidence, the confidence to apply mathematics, was also of interest because students should be prepared for their future lives, not only for success at university. Many jobs in engineering require competency in mathematics and it is beneficial for students to feel confident that they will be competent in this respect at work in the future, and also in the later parts of their course.

Overall Confidence in Mathematics had been investigated in the US and was called 'math selfconcept', but was not known to have been used in a UK university before. One definition of the american term Self-concept is 'the idea or mental image one has of oneself and one's strengths, weaknesses, status, etc.' (Random House Inc., 2006). In the US Topic Confidence is known as 'self-efficacy.' Warwick (2008) cites Bandura's (1997) definition of self-efficacy as 'people's judgements of their capabilities to organise and execute courses of action required to attain designated types of performance'. Pajares and Miller (1994) state that 'Self-concept differs from self-efficacy in that self-efficacy is a context-specific assessment of competence to perform a specific task'... 'Self-concept is not measured at that level of specificity and includes beliefs of self-worth associated with one's perceived competence.' Thus 'math self-efficacy' is considered comparable to Topic Confidence, and 'math self-concept' comparable to the 'Overall Confidence in mathematics' defined in this study.

Overall Confidence in Mathematics also differs from Topic Confidences in that it is generally a more stable measure, being slower to form and change, unlike Topic Confidences which can be changed in a relatively short space of time, e.g. a lecture or tutorial. It is possible to envisage individuals whose Topic Confidences and Overall Confidence in Mathematics are very different values. For example, a mature student who was previously good at mathematics could have a high Overall Confidence in Mathematics, but have forgotten most of the maths he once knew and would thus have low Topic Confidences. Conversely someone who has formed their opinion that they 'can't do maths', then despite successfully learning some topics (thus having high Topic Confidences in these topics) persists with their low Overall Confidence in Mathematics. This latter case is a sad example and is less able to learn independently than the former.

Warwick (2008) describes a study of undergraduate students studying mathematics as part of a computing degree at London South Bank University, in which he investigated means to enhance students' self-efficacy and their engagement with mathematics. Whilst he did not differentiate between self-efficacy and self-concept beliefs, he describes clearly Bandura's four main sources of evidence which generally contribute to an individual's self-efficacy beliefs. These are: performance evidence (success raises self-efficacy whereas failure lowers it) which is the 
strongest source of evidence, vicarious experiences (comparison with peers, colleagues and classmates), verbal persuasions (comments and feedback from others), and physiological and affective states (inner feelings of worry, anxiety or alternatively confidence and enjoyment which may be experienced when undertaking mathematical tasks).

In the next section we will describe our methodology for gathering data and assessing student confidence, attitude and motivation.

\section{Methodology}

In May 2005, 2006 and 2007 questionnaires were administered to first year engineering students at Harper Adams seeking their views on learning mathematics. Open and closed questions gathered information on qualifications, confidences, attitudes, motivation and students' views on the modules and support provided. These questionnaires were part of a larger study which included second year students and students on other courses, which are not described in this paper.

The number of questionnaires completed by first year engineering students was 29, 50 and 32 in years 2005, 2006 and 2007 respectively, 111 in total. The annual entry into first year engineering programs is relatively small, approximately 55, thus a good response rate (approx. 50-60+\%) was achieved. Students' responses related primarily to their mathematics modules, however the students also studied statistics, using mathcad software, to which some responses referred.

The questionnaires were administered by three different lecturers in the final mathematics lectures of the year. In 2005 the BSc group completed a pilot questionnaire, after which small modifications were made. In subsequent years the BSc and HND/FdSc groups completed identical versions of the questionnaires. However, there were separate BEng/MEng versions of the questionnaires, reflecting the more challenging BEng/MEng syllabus for Topic Confidence questions.

Objective data including Age, Gender, Mathematics GCSE Grade, whether the student had studied ' $A$ ' level Mathematics was gathered at the start of the questionnaires. More subjective data, including confidences, liking of mathematics, motivation and attitude was gathered using a mixture of closed questions (generally 5 point Likert scales) and open questions. See the Key questions in Appendix I.

Questions were posed according to three domains of confidence: Overall Confidence in Mathematics, a Topic Confidence for each of eleven topics studied in the module, and Applications Confidence. The questions relating to these three domains of confidence are described in further detail below.

For Overall Confidence in Mathematics, students were asked to rate their Confidence in Mathematics, Confidence in Statistics, and whether the student felt more confident after the mathematics module. Confidence in Life was also asked for, because it was considered that 
some people would be naturally more positive thereby providing another benchmark with which to compare students' responses. See key questions 2-4 and 7 in Appendix I. Topic Confidences for eleven topics and Applications Confidence in the future were also asked for. It was expected that the Topic Confidences would vary according to their perceived difficulty and students' familiarity with the topic. See Section 4.1.

The range of questions about confidence was expanded in 2006 and 2007, by asking students to rate their agreement with various statements including 'I don't have a mathematical mind', to create a confidence scale, which was based on Fogarty et al, 2001. The analysis of this wider range of questions is outside the scope of this paper, but it was found that student ratings for their Overall Confidence in Mathematics were verified and found to be consistent with the more detailed work.

Student attitudes were collected by three questions: an open question 'How would you describe your attitude to learning mathematics?' and closed questions: asking students to rate their Liking of Mathematics (1-5) and to rate their Liking of Statistics (1-5), where 5 was high. See key questions 8-11 in Appendix I.

Students' motivation was collected by four questions: asking students whether they would have chosen to study the module (Y/N), to rate their Motivation (1-5), to state whether this was more, less or the same as for other modules (M, L or S) and to give an approximate number of hours spent working on mathematics outside of lectures in a week. See key questions 1 and 12-14 in Appendix I.

Questionnaire responses were analysed using Excel, SPSS and Genstat for quantitative data, and by identifying themes and common responses for open questions.

\section{Results}

\subsection{Results of Closed Questions}

Mean student responses from the 2005-7 questionnaire key closed questions and mean mathematics marks are shown by award group in Table 1 below, and in Figures 1 and 2. Student confidences, liking and Motivation were measured using Likert scales, from 1 to 5 (5=high).

Considering the totals and overall mean responses, the first year engineering students had medium to good confidence in their ability to do mathematics, as demonstrated by mean ratings above 3 in all cases. $72 \%$ of students responded that they felt more confident in mathematics at the end of the first year, and the mean response to whether students felt more confident after the mathematics module was 4.0 (out of 5). 
Table 1. Summary of 2005, 2006 and 2007 First Year Engineers’ Responses

\begin{tabular}{|c|c|c|c|c|c|c|c|c|c|c|c|c|}
\hline \multirow[b]{2}{*}{$\begin{array}{l}\text { First Year } \\
\text { Student } \\
\text { Group }\end{array}$} & \multirow[b]{2}{*}{ 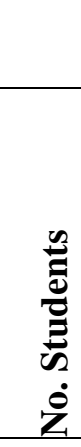 } & \multicolumn{4}{|c|}{ Confidences } & \multicolumn{3}{|c|}{ Liking } & \multicolumn{3}{|c|}{ Motivation } & \multirow[b]{2}{*}{ 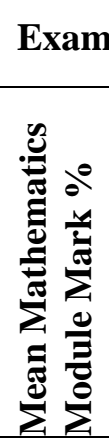 } \\
\hline & & 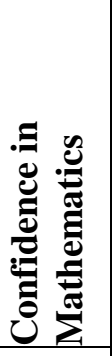 & 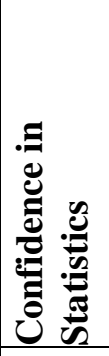 & 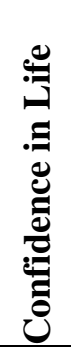 & 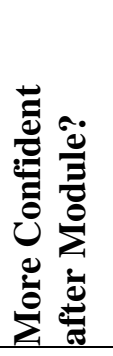 & 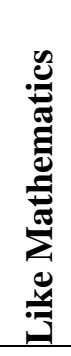 & 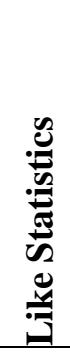 & 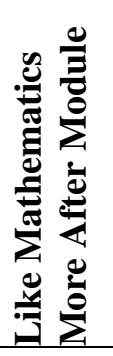 & 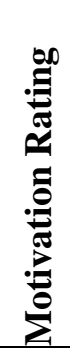 & 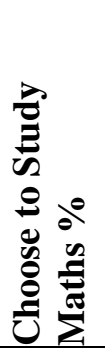 & 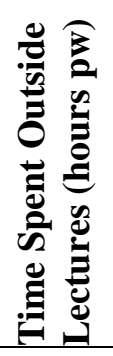 & \\
\hline M/BEng & 38 & 3.6 & 3.1 & 3.7 & 4.0 & 3.6 & 2.7 & 3.6 & 3.6 & 87 & 1.3 & $78.4 \%$ \\
\hline BSc & 50 & 3.5 & 2.9 & 3.7 & 4.3 & 3.6 & 2.8 & 3.8 & 3.4 & 76 & 1.1 & $69.3 \%$ \\
\hline HND/FdSc & 23 & 3.2 & 2.9 & 4.0 & 3.7 & 3.1 & 2.5 & 3.1 & 3.3 & 35 & 1.8 & $43.5 \%$ \\
\hline $\begin{array}{l}\text { Grand } \\
\text { Totals }\end{array}$ & 111 & 3.5 & 3.0 & 3.8 & 4.0 & 3.5 & 2.7 & 3.6 & 3.4 & 71 & 1.3 & $67.2 \%$ \\
\hline
\end{tabular}

Student's mean Liking of mathematics was fairly high (3.5 out of 5) and their attitudes (open question) were generally positive towards mathematics. See the responses to the open question regarding attitude in the next section.

First year engineers were fairly motivated: average Motivation 3.4 and overall $71 \%$ would choose to study mathematics. The mean time spent working on mathematics outside of lectures was 1.3 hours per week according to the student responses.

Student responses regarding statistics were lower than for mathematics, both their confidence in their ability to do statistics (mean value 3.0), and students' Liking of Statistics (mean value 2.7, the only mean rating less than 3 ) were lower than the equivalents for mathematics. It was not clear whether this related to statistics as a subject or to the use of mathcad.

The overall mean mathematics module mark, the average of three termly examinations, was $67.2 \%$, indicating good achievement for the students who completed the questionnaires.

Mean student ratings by award group are shown below in Figure 1. Generally the MEng/BEng students were the most confident, liked mathematics more and were more motivated in mathematics than the BSc students, whose confidence, liking and motivation were higher than those of the HND/FdSc students, even though the MEng/BEng curriculum and exams were harder. The BSc students reported the greatest increase in Confidence in Mathematics and Liking of Mathematics, and the HND/FdSc students had the greatest Confidence in Life.

Confidence in Life was often found to follow an opposite pattern to Confidence in Mathematics, high Confidence in Mathematics was often found in students with lower Confidence in Life and vice versa. The HND/FdSc students reported the lowest Confidence in Mathematics (3.2) and lowest Confidence in Statistics (2.9), but the highest Confidence in Life (4.0) which further 
highlights the potential for improvement in their confidence in their ability to do mathematics and statistics. The HND/FdSc students were generally the least mathematically qualified, thus these findings were consistent with findings shown later regarding GCSE mathematics grades.

Overall students' Confidence in Life was greater than for Confidence in Mathematics, which was greater than their Confidence in Statistics (their ability to do statistics). Almost all mean ratings were over 3 (the middle possible value) except for confidence and liking ratings for statistics which were lower, almost all below 3. See Figure 1. Please see Appendix I. for the whole wording of questions shown on the horizontal axis.

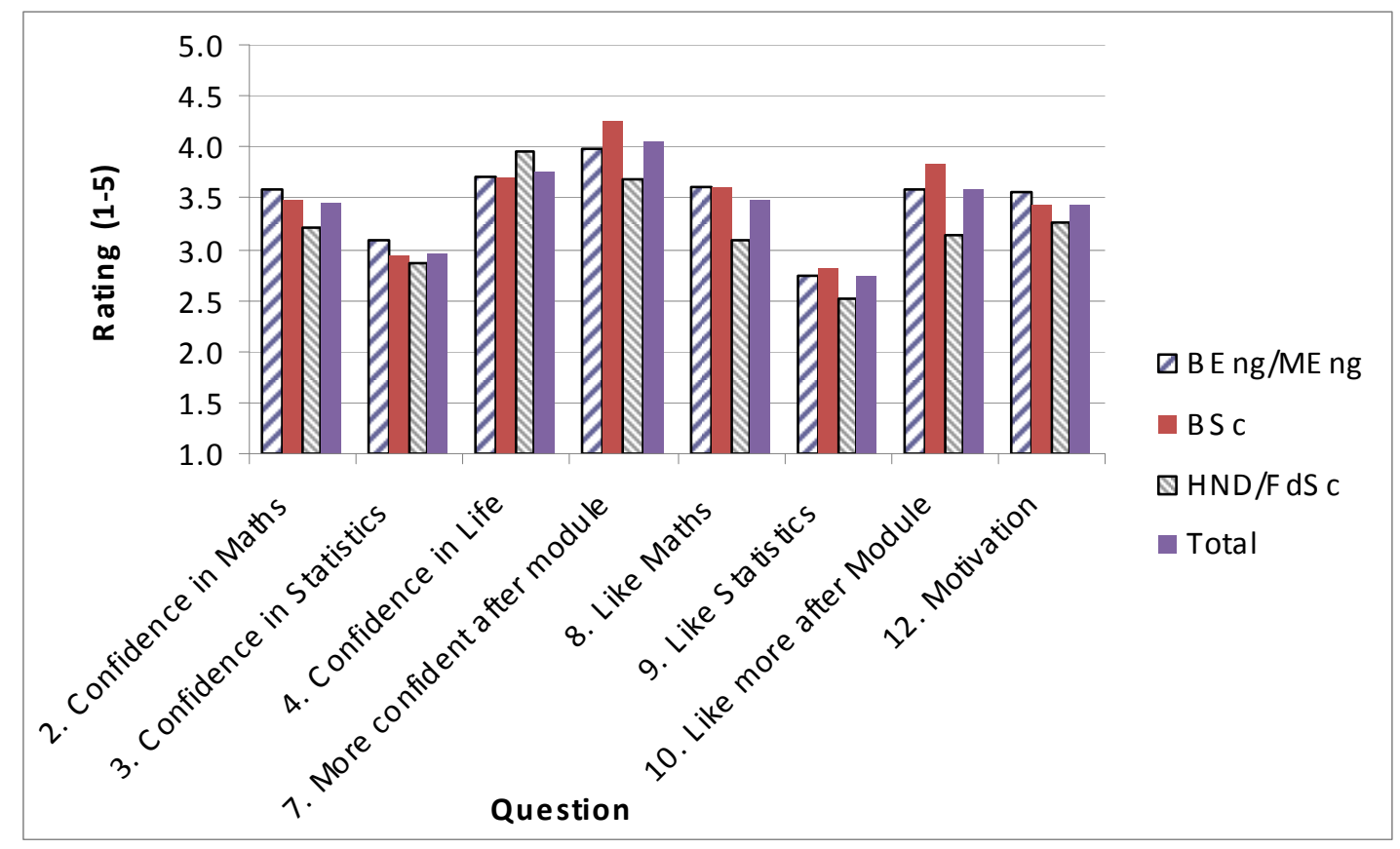

Figure 1. 2005, 2006 and 2007 Confidences, Liking and Motivation Mean Ratings by Award Group

Student achievement for the MEng/BEng and BSc students surveyed was good with high mean examination marks, whereas HND/FdSc students achieved lower results, see Figure 2. 


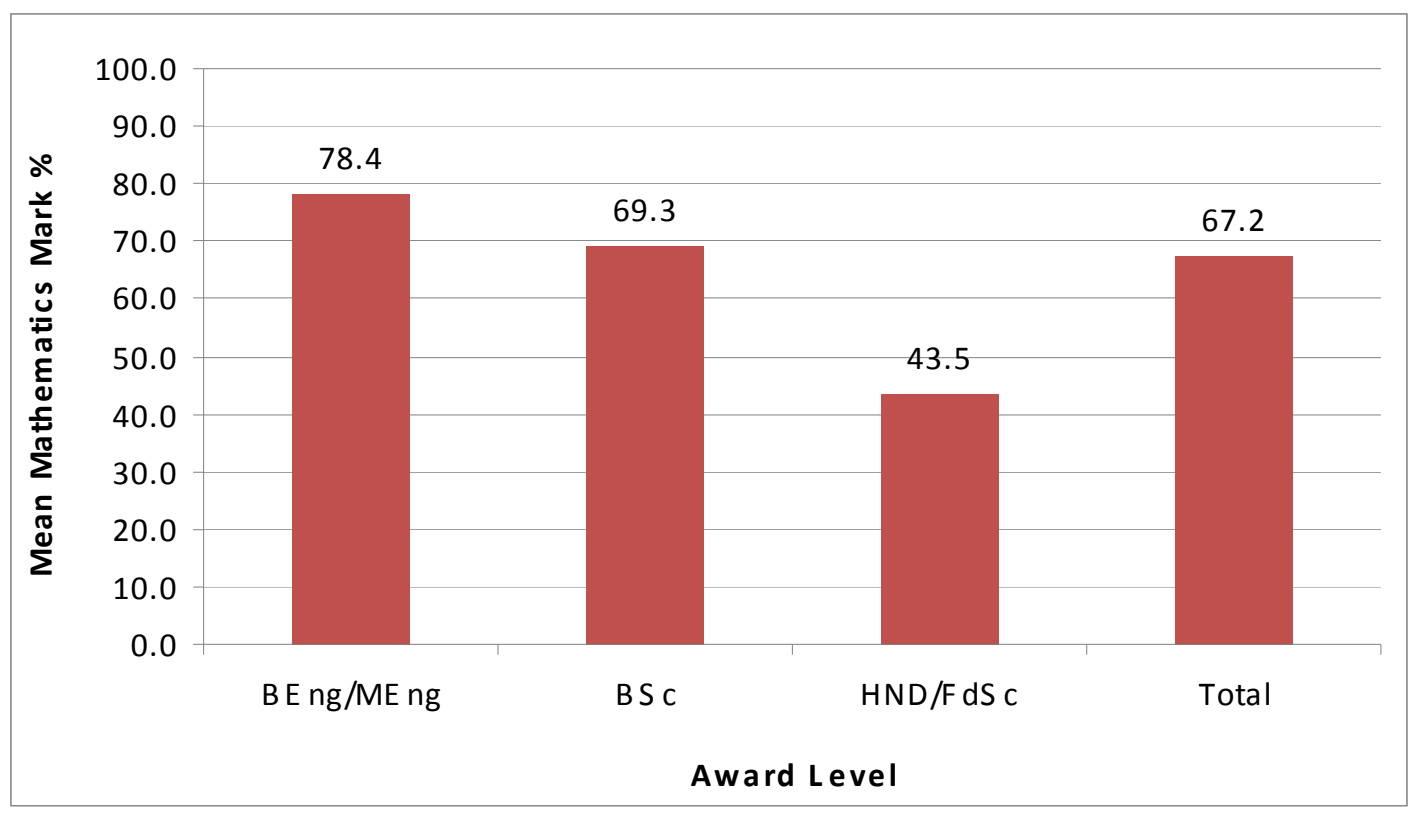

\section{Figure 2. Surveyed Students’ Mathematics Marks by Award Level}

The results for the eleven Topic Confidences were varied, as expected, and were often slightly higher than the students' overall Confidence in Mathematics as one might hope for, as students had recently been taught and practised these topics. Student responses regarding Applications Confidence in the future fell into two categories: less confident which some explained that they would have forgotten the mathematics by then, whilst others would be more confident because they would have learned and practised the mathematics more.

\subsection{Results of Open Questions}

Open questions on the questionnaires revealed varied opinions and were generally consistent with the closed question mean ratings. Student attitudes towards studying mathematics (see Question 11 in Appendix I) were often positive (e.g. 'good attitude' 'positive', willing to learn', 'hard working and positive' $27 \%$ of responses), 'OK' or 'Alright' (11\% of responses ), and many students understood that Mathematics was necessary for engineering (e.g. 'It has to be done so you might as well get on and do it', 'A necessity', 18\% of responses). This necessity appears to override a lack of confidence or dislike of the subject and appears to be a powerful motivator.

Some students reported that their confidence was established a long time ago (see Question 5. in Appendix I), e.g. a long time, forever, always (25\%), or during secondary school (26\%), and some responses (20\%) described confidence held since learning mathematics at Harper Adams. This was consistent with closed question responses which showed that many students had gained confidence at Harper. Students' previous experiences (see Question 6. in Appendix I) were very mixed (e.g. overall good experiences 19\%, overall bad experiences 17\%). A noticeable number of students, 9 (8\%), described past problems specifically arising during A-level mathematics. The students' responses to what had helped their learning, included: good teaching, mathematics support, and handouts. 
Overall the students' responses show mixed experiences before university, as would be expected, but were generally positive about learning mathematics at Harper Adams.

\section{Analysis and Discussion}

\subsection{Relationships between Mathematics Module Marks, GCSE Mathematics Grades and Confidence in Mathematics}

Students with higher GCSE mathematics grades generally achieved higher marks in the mathematics modules. GCE A-level mathematics details were not present for all students surveyed, because not all the students had studied A level mathematics (e.g.Scottish or Irish students), and therefore could not be used in these analyses. Because only one student reported achieving GCSE mathematics grade $A^{*}$, grades $A$ and $A^{*}$ were combined. Likewise, due to a single grade $\mathrm{E}$, grades $\mathrm{D}$ and $\mathrm{E}$ were also combined. Ten students had blank or numeric GCSE mathematics grades (possibly Scottish) which were excluded, and also those students who did not provide their student id number could not be linked to their module marks.

Figure 3 shows that the mean mark for students with GCSE mathematics grade A or A* was $81 \%$, and that mean university marks decreased for lower GCSE grades, down to $40 \%$ for mathematics grades $\mathrm{D}$ or $\mathrm{E}$. The student numbers represented by the columns (Grades $\mathrm{A} / \mathrm{A}^{*}$ to D/E) were: 22, 44, 27 and 4 respectively.

An ANOVA test was carried out which found a significant difference between the university marks in mathematics for students with different grades at GCSE Mathematics $(\mathrm{P}<0.001)$, students with higher mathematics GCSE grades generally achieved higher first year mathematics marks.

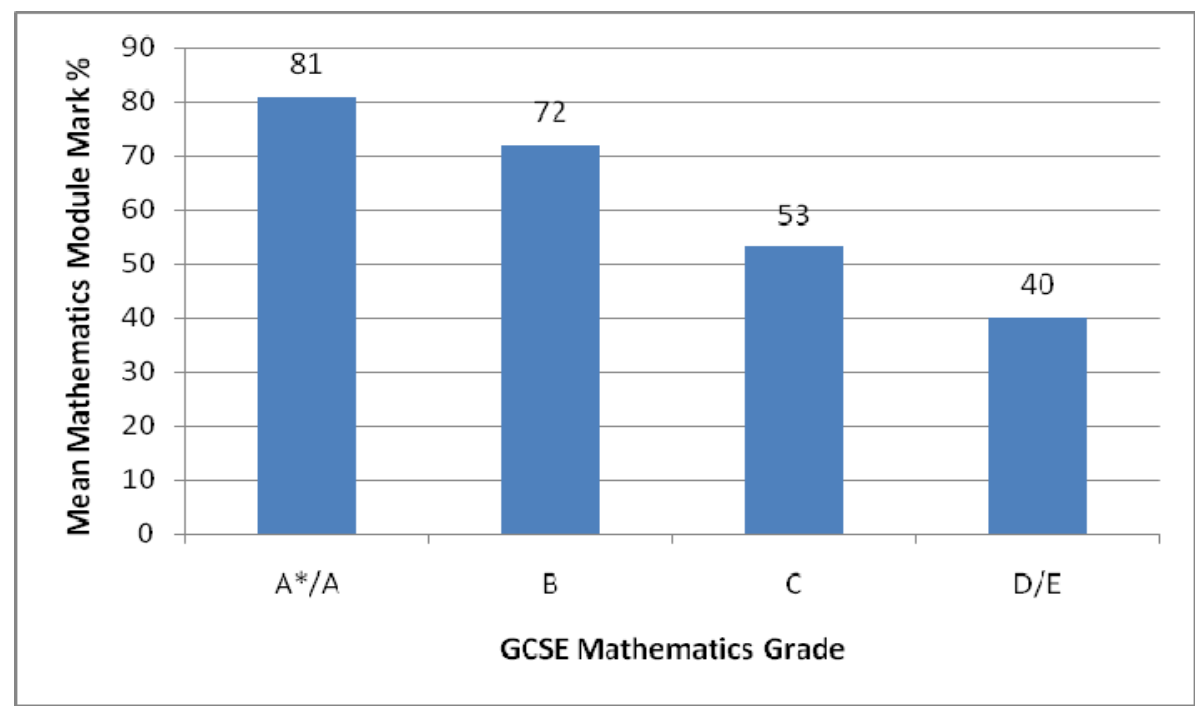

Figure 3. 2005-7 Mean Mathematics Marks by GCSE Mathematics Grade 
Students with higher GCSE mathematics grades generally reported higher confidence in their ability to do mathematics. Figure 4 shows the mean Confidence in Mathematics for students with GCSE mathematics grade A or A* was 3.7 and that mean confidence decreased as GCSE grade decreased, down to 2.8 for grades $\mathrm{D}$ or $\mathrm{E}$. The student numbers represented by the columns (Grades A/A* to D/E) were: 22, 48, 27 and 4 respectively. The students' confidence ratings were taken at the end of their first year at university and not straight after GCSE, which might have produced a clearer trend.

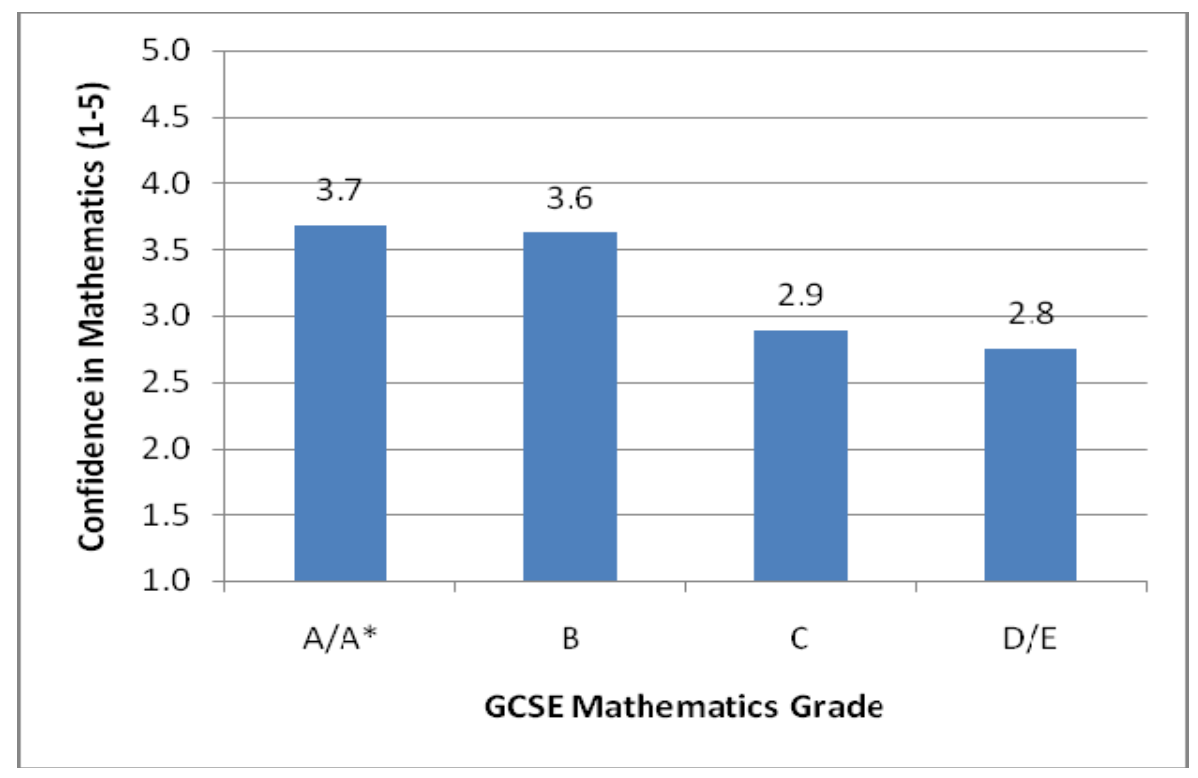

Figure 4. 2005-7 Mean Confidence in Mathematics by Mathematics GCSE Grade

A Kruskal-Wallis test was carried out, which found a significant difference between the confidences of students with different GCSE Mathematics grades $(\mathrm{P}<0.001)$. The KruskalWallis test, a non-parametric equivalent of ANOVA, was carried out because the confidences were ranks and whilst these might have approximated to an interval scale, this test does not rely on the underlying assumption of interval data (but can also be used with interval data). In order to carry out the Kruskal-Wallis test some categories were combined to remove low counts: confidence 1 with 2, confidence 4 with 5, and GCSE grade C with D/E.

Students with higher Confidence in Mathematics achieved higher marks in first year engineering mathematics. An ANOVA test confirmed there was a significant difference between the marks achieved by students with different Confidences in Mathematics $(\mathrm{P}<0.001)$. Figure 5 shows a mean mark of $43 \%$ for students with the lowest Confidence in Mathematics (1), and that mean marks increased as Confidence in Mathematics increased, up to $80 \%$ mean mark for students with the highest Confidence in Mathematics (5). The student numbers represented by the columns (confidences 1 to 5) were: 5, 8, 40, 47 and 11. 


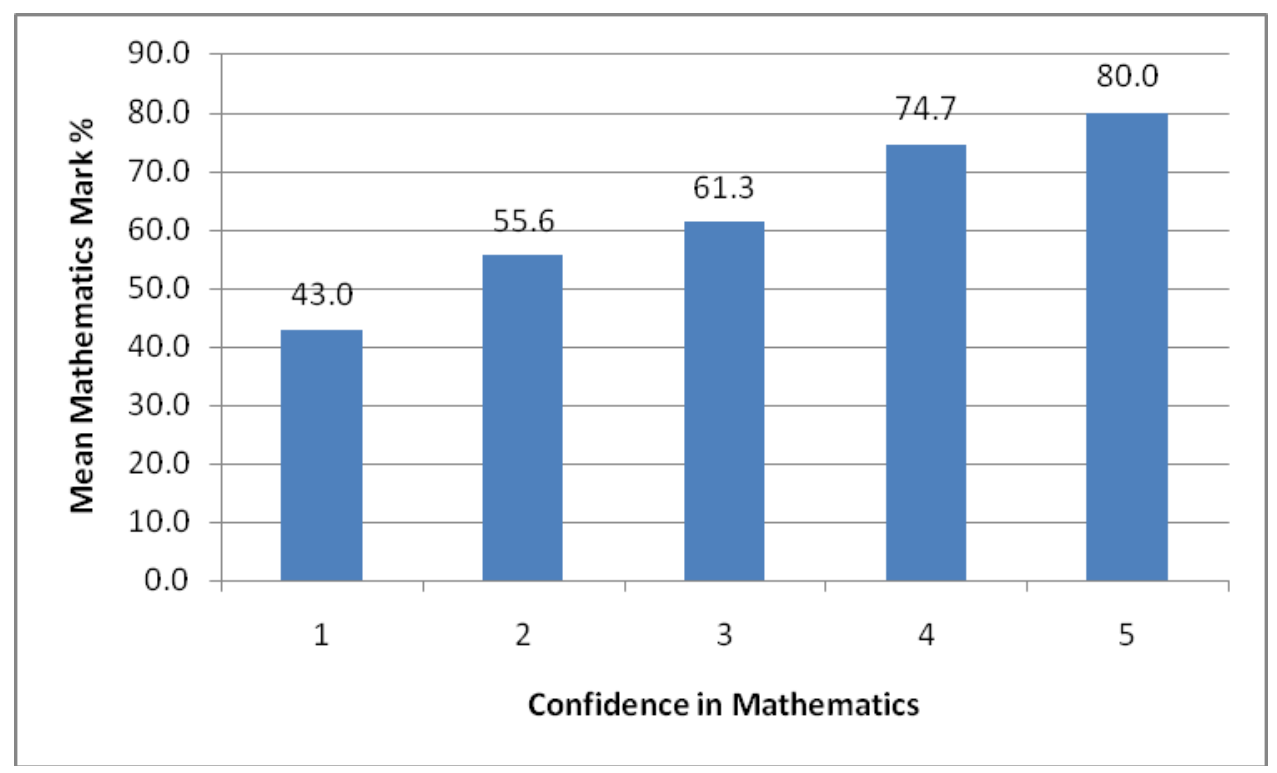

Figure 5. 2005-7 Mean Mathematics Mark by Confidence in Mathematics

\subsection{Relationships between Mathematics Module Marks and Other Factors}

ANOVA tests were performed to test which factors had a significant effect on (or relationship with) students' marks in first year engineering mathematics.

Student mathematics marks were found to be very highly significantly $(\mathrm{P}<0.001)$ related to award level (M/BEng, BSc, HND/FdSc), GCSE mathematics grade, GCSE mathematics tier, whether students had studied A-level mathematics, whether students would choose to study the mathematics module, Confidence in Mathematics and Liking of Mathematics. This analysis did not, however, prove cause and effect.

The following factors were also considered but did not give significant relations with mathematics marks: University Course, Age, Dyslexia, Confidence in Life, Time spent working outside lectures and whether students used Mathematics Support. Analysis outside the scope of this paper showed that Mathematics Support was a value added measure, generally improving the marks of students with lower qualifications.

The results of the ANOVA tests were that significant relationships were found consistent with section 5.1, that higher achievement in mathematics at university was associated with higher past achievement and higher Confidence in Mathematics at university.

\subsection{Correlation and Regression Analysis}

Correlation and regression analysis was carried out to find a model to explain the students' university mathematics marks based on their GCSE mathematics grade, Confidence in Mathematics, Liking of Mathematics and Motivation rating (where the Confidence in 
Mathematics is a variable used to measure the domain Overall Confidence in Mathematics). For the purpose of this regression analysis the independent variables were recoded: GCSE Mathematics grades were coded as $\mathrm{A} / \mathrm{A}^{*}=3, \mathrm{~B}=2, \mathrm{C}=1, \mathrm{D} / \mathrm{E}=0$, and the 5 point Likert scale values were reduced by 1 to $0-4$ (from 1-5).

Table 2 below shows that each of these variables was found to be significantly correlated with the mathematics module marks (the dependent variable). The 'independent' variables are listed in order of the correlation coefficient, showing that mathematics GCSE grade was the most correlated with the mark, followed by Confidence in Mathematics, then Liking of Mathematics, then Motivation.

Table 2. Correlation Coefficients for Correlation with Mathematics Module Marks

\begin{tabular}{|l|c|c|}
\hline Independent Variable & $\begin{array}{c}\text { Pearson Correlation } \\
\text { Coefficient }\end{array}$ & Significance \\
\hline Mathematics GCSE Grade & 0.572 & .000 \\
\hline Confidence in Mathematics & 0.437 & .000 \\
\hline Liking of Mathematics & 0.347 & .000 \\
\hline Motivation in Mathematics Module & 0.274 & .004 \\
\hline
\end{tabular}

A correlation matrix was also produced to check the correlations between the 'independent' variables, and the result was that these were not independent variables due to significant correlations between them. Thus it was not possible to produce a model to predict the module mark which contained all the above variables with significant coefficients for each independent variable. The cause of this could be explained by considering that although Confidence in Mathematics, Liking of Mathematics and Motivation were different attributes of students, their responses to these questions were often numerically similar.

It was, however, possible to produce models to predict the module mark using (as independent variables) the GCSE mathematics grade and only one of the other variables: Confidence in Mathematics, Liking of Mathematics or Motivation. The resulting R and R-Square values are shown in Table 3 below, showing broadly similar values for the three models.

Table 3. Regression Model Summaries for Mathematics Module Marks

\begin{tabular}{|c|c|c|c|c|}
\hline \multicolumn{2}{|r|}{ Independent Variables } & $\underline{\mathbf{R}}$ & R-Square & $\frac{\text { Adjusted R - }}{\text { Square }}$ \\
\hline \multirow{3}{*}{$\begin{array}{c}\text { Mathematics GCSE } \\
\text { Grade }\end{array}$} & Confidence in Mathematics & 0.609 & 0.371 & 0.358 \\
\hline & Liking of Mathematics & 0.607 & 0.368 & 0.355 \\
\hline & Motivation in Mathematics Module & 0.611 & 0.373 & 0.360 \\
\hline
\end{tabular}


The model using GCSE mathematics grade and Confidence in Mathematics gave R-Square = 0.371 , i.e. $37.1 \%$ of the variation in student marks was explained by this model. The equation to predict the mathematics module mark produced by this model was:

Mark \% $=31.9+12.3$ x GCSE Grade + 5.2 x Confidence in Mathematics

This model shows a baseline mark of $31.9 \%$ for a student with the lowest GCSE mathematics grade and lowest confidence (1). Each higher grade achieved at GCSE adds $12.3 \%$ to the student's predicted mark, and each higher Confidence in Mathematics adds 5.2\% to the student's predicted mark.

This model seems very reasonable when compared to the actual mean marks by GCSE grade, where some of the differences between marks for each grade are similar to 12\%. See Figure 3 . Likewise, the increases in mark for increased Confidence in Mathematics can also be seen to be similar to the $5.2 \%$ predicted by the model. See Figure 5.

The other linear regression models produced to predict the mathematics module mark (\%) were similar to that shown above for GCSE mathematics grade and Confidence in Mathematics, but were produced using GCSE mathematics grade with either Liking of Mathematics or Motivation.

Mark \% $=30.5+12.6$ x GCSE Grade + 5.5 x Liking of Mathematics

Mark \% $=28.2+13.6$ x GCSE Grade +5.7 x Motivation

In all three models there is a baseline mark of approximately 30\% for the students with low GCSE mathematics grade and low Confidence or Liking or Motivation (1). Each higher GCSE mathematics grade adds approximately $12-13 \%$ to the mark, and each higher confidence, liking or motivation adds approximately $5-6 \%$ to the mark. All three models are similar in explaining approximately $37.1 \%$ of the variation in student marks. The Adjusted R-Square values allow the comparison of models with differing numbers of variables and again all three models are approximately equivalent (Adjusted R-Square approx. 0.36). The purpose of creating these models was however to ascertain approximate or relative portions to the effects of different factors (independent variables), and was not to obtain precise values for the coefficients.

Students' mathematics GCSE grade is fixed. However their confidence, liking and motivation can be changed at university, albeit slowly according to Kent and Noss (2003). These models indicate that whilst past qualifications produced the greatest effect, the effect of these subjective and potentially modifiable attributes was measurable and worth paying attention to.

\section{Conclusions}

The methodology adopted was generally successful. Students completed the questionnaires with meaningful responses which provided insight into their experiences and domains of confidence. The three domains of confidence were found to work as defined. Minimal changes were made to the questions shown in the Appendix for the successive years, but Applications Confidence was 
changed from being by topic to a single rating. In addition, in 2006 a bank of 11 scale questions were included to compare with the single Confidence in Mathematics rating, which produced similar results (and a smaller set of scale questions were also posed in 2007), although not detailed in this paper. More detailed questions and responses on A-level mathematics module results would have been useful. Overall the surveys contained useful information and generally consistent responses from the years surveyed.

The experiences of Harper Adams first year engineering students were mixed for learning mathematics before university, but generally positive at university. To determine why, the students' responses to what had helped their learning provided the most relevant details, including: good teaching, mathematics support, and handouts. The majority of engineers (71\%), would have chosen to study mathematics and were fairly well motivated. Many had positive attitudes to learning mathematics. Students reported a range of levels of confidence in their own ability in mathematics, and the mean Confidence in Mathematics was good, above 3 (out of 5). Comparing engineering students' confidence in their abilities gave on average: Confidence in Life higher than Confidence in Mathematics which was higher than Confidence in (their ability in) Statistics. The majority of students, $72 \%$, reported an increase in confidence during the year. Whilst students were not asked explicitly what they thought had caused this, the most likely causes were: their success at the subject, both when working on examples during the year and good termly examination results, small class sizes, good teaching, mathematics support and student handouts. This is an area which at the time of writing was being explored further in student interviews.

Relationships were found between students' entry qualifications (Mathematics GCSE Grade and whether they had studied A-level mathematics), students' Confidence in Mathematics and their achievement in university engineering mathematics. Higher achievement in mathematics at university was associated with higher past achievement and higher Confidence in Mathematics at university. These relationships were tested and found significant using ANOVA and KruskalWallis tests, correlations and regression models. Age, Dyslexia and the time spent working outside lectures were shown to not have a significant effect on mathematics marks.

Correlation and Regression analysis was carried out which found a model predicting the mathematics marks comprising a baseline mark of approximately $30 \%$, and that marks increased by $12-13 \%$ for each higher GCSE mathematics grade, and by 5-6\% for each increase in Confidence in Mathematics.

Students with the lowest GCSE grades were generally the least confident and least successful in mathematics; it is recommended that these students should be identified and targeted with extra help and confidence building. At Harper Adams these students are identified in the first weeks of the year by the numeracy screening process and are brought to the lecturer's attention and encouraged to seek support. Other institutions could also benefit from identifying the students with the lowest qualifications and ensuring that they take up any support available.

A main aim of the work reported in this paper was to investigate the relationship between confidence and achievement. Warwick (2008) investigated self-efficacy and student engagement. His recommendations included: giving feedback to students on particular aspects 
of the work when deserved (not just a general 'well done'), that real enhancements to efficacy stem from successful completion of more difficult tasks, and that students should be made aware that mathematical competence and ability are changeable and can be developed through practice and experience. Warwick concluded that increasing student self-efficacy in itself improves student engagement in mathematics and suggests other more general means to improve student engagement (for example emphasising the real world relevance of the subject, which was also a finding in the present study not described in this paper).

Students' confidence in their ability in mathematics was shown by this present study to have significant relations with performance both before and at this university college, but not proven to be causal. Whilst a majority of students were shown to be confident and successful, a minority were not, so there was room for further improvement. Mathematics lecturers rightly concentrate on teaching mathematical skills and knowledge, but these findings indicate that students' confidence in their ability in mathematics does matter. Students' achievement and experiences could be further improved if university lecturers also sought to boost students' confidence in their ability in mathematics. Regarding nurturing academic confidence, Pajares (2000) stated 'Efficacious teachers create classroom climates in which academic rigor and intellectual challenge are accompanied by the emotional support and encouragement necessary to meet that challenge.'

\section{References}

Armstrong, P. K. and Croft, A. C. 1999. Identifying the Learning Needs in Mathematics of Entrants to Undergraduate Engineering Programmes in an English University. European Journal of Engineering Education, 24(1), 59-71.

Brown, M., Bartholomew, H. and Rodd, M. 2003. An examination of one Group of Failing Single Honours Students in One University. MSOR Connections. 3 August. 17-20.

Carmichael, C. and Taylor, J.A. 2005. Analysis of student beliefs in a tertiary preparatory mathematics course. International Journal of Mathematical Education for Science and Technology, 36 (7).

Croft, A.C. 2005. Confidence Questionnaire for First Year Computer Science Students. (unpublished).

Ernest, P. 1991. The Philosophy of Mathematics Education. London: Falmer Press. In: Ernest P., The Mathematical Attitudes, Beliefs and Ability of Students.

'Maths for Engineering and Science'. LTSN MathsTEAM. 4-5.

Ernest, P. 2000. Mathematics and Special Educational Needs'. University of Exeter. In: Ernest P., 'The Mathematical Attitudes, Beliefs and Ability of Students'. 'Maths for Engineering and Science'. LTSN MathsTEAM. 4-5. 
Fishbein, M., \& Ajzen, I. 1975. Belief, attitude, intention and behavior: An Introduction to theory and research. London: Addison-Wesley Publishing Company.

Fogarty, G., Cretchley, P., Harman, C., Ellerton, N., \& Konki, N. 2001. Validation of a questionnaire to measure mathematics confidence, computer confidence, and attitudes towards the use of technology for learning mathematics. Mathematics Education Research Journal, 13(2), 154-160.

Frid, S., Goodell, J. T. and White, B. 1997. Identifying Avenues for Curriculum Development in Undergraduate Mathematics. In: proceeedings of the Annual Meeting of the American Educational Research Association, Chicago 24-27 March 1997.

Hawkes, T. and Savage, M. D. 2000. Measuring the Mathematics Problem. London: Engineering Council.

Kent, P. and Noss, R. 2003. Mathematics in the University Education of Engineers. [On-line]. The Ove Arup Foundation. Available from:

http://www.theovearupfoundation.org/arupfoundation/pages/download25.pdf [Accessed 4 February 2006].

Pajares, F. and Miller, M. D. 1994. Role of Self-efficacy and Self-Concept Beliefs in Mathematics Problem Solving: A Path Analysis. Journal of Educational Psychology, 86 (2), 193-203.

Pajares, F. 2000. First person: Frank Pajares on nurturing academic confidence. [On-line]. Emory University. Available from:

http://www.emory.edu/EMORY_REPORT/erarchive/2000/February/erfebruary.14/2_14_00pajar es.html [Accessed 8 October 2008].

Parsons, S. 2005. Success in engineering mathematics through mathematics support and changes to engineering mathematics modules at Harper Adams. MSOR Connections. 5 (1), p.31-34.

Random House Inc., 2006. Self-concept definition. [On-line]. Ask.com. Available from: http://dictionary.reference.com/browse/self-concept [Accessed 8 October 2008].

Warwick, J. 2008. Mathematical self-efficacy and student engagement in the mathematics classroom. MSOR Connections. 8 (3), p.31-37 


\section{Funding}

This work was supported by Harper Adams University College by a 2005-6 Aspire CETL (Centre for Excellence in Teaching and Learning) Development Fellowship Award to S. J. P. for part of this study.

\section{Acknowledgements}

Statistics advice was given by Dr. Richard Gadsden, Lecturer in Statistics in the Mathematics Education Centre at Loughborough University.

\section{Appendix I}

\section{KEY QUESTIONS}

The following questions are a subset of the questions in the student questionnaires, which corresponds to the results being presented in this paper. The original questionnaires contained approximately 50 questions in total.

1. Given a choice would you have chosen to study this mathematics module?

$$
\text { Yes } \square \quad \text { No }
$$

How confident would you describe yourself overall?

Please tick one box per question

$$
\text { Very confident } \quad \text { Not confident }
$$

2. in mathematics?

3. in statistics?

4. in life in general?

5. For how long have you held this opinion of your self-confidence in mathematics?

6. How do you think that your experiences of mathematics before coming to university have affected your confidence or liking of the subject?

(Please describe your experiences if possible)

7. Has this module helped you to feel more confident than previously? 
Do you like the subject?

$$
\text { Really Like Detest }
$$

8. Like Mathematics?

9. Like Statistics?

10. Has this module helped you to like the subject more?

$$
\text { More }
$$

11. How would you describe your attitude to learning mathematics?

12. How would you rate your motivation in this area?

$$
\text { Really motivated }
$$

13. Is this more or less motivation than for your other modules overall? More $\square \quad$ Less $\square \quad$ The same

14. How much time have you spent outside lectures working on this module on average in hours per week? (tick one box)
$0 \square$
1 hour
2 hours
3 hours
$4+$ hours 


\section{Author Details}

Sarah J. Parsons is a Senior Lecturer in Engineering Mathematics and also the Mathematics Support Tutor at Harper Adams University College. She is a part-time research student with the Mathematics Education Centre at Loughborough University, which is part of the Sigma CETL. Her research interest is mathematics and statistics learning by non-specialist students.

e-mail: sjparsons@harper-adams.ac.uk

Engineering Department

Harper Adams University College

Newport

Shropshire

TF10 8NB

Tel: 01952815448

Tony Croft is Director of the Mathematics Education Centre at Loughborough University, a HEFCE designated Centre for Excellence in Teaching and Learning. His particular research interest is mathematics support at university level. He is the author of several books aimed at this audience. Tony is a director of mathcentre, the on-line UK-wide mathematics learning support centre.

e-mail: a.c.croft@lboro.ac.uk

Mathematics Education Centre and Sigma CETL

Loughborough University

Leicestershire

LE11 3TU

Tel: 01509223185

Martin Harrison is Associate Dean (Teaching) for the Faculty of Science at Loughborough University. His research interests include policy and practice of mechanics education in the UK, mathematical confidence and curriculum development. Martin has been Editor of iJMEST (International Journal of Mathematical Education in Science and Technology) since 1997.

e-mail: m.c.harrison@lboro.ac.uk

Faculty of Science

Loughborough University

Leicestershire

LE11 3TU

Tel: 01509222871 